\title{
Pregnancy Care: An Apprenticeship for Palliative Care?
}

\author{
W. David Clark, $M D$
}

The American Board of Medical Specialties has recently recognized palliative medicine as a new subspecialty. Family Medicine was one of 10 specialty boards cosponsoring this certification process. The role of the family physician has many parallels in the care of pregnant and dying patients. The family physician that has provided maternity care can apply his or her experiences to their care of the dying. The reader is invited to consider this possibility as part of an intentional transition to palliative medicine. (J Am Board Fam Med 2008;21:63-65.)

“After all, we didn't bring anything with us when we came into the world, and we certainly cannot carry anything with us when we die."

-Apostle Paul, First Letter to Timothy 6:7, New Living Translation

"Birth and death are the two noblest expressions of bravery." —Kahlil Gibran

One of my mentors from residency once said that a physician's 2 greatest privileges were to attend a woman in labor and care for a dying patient. In my 30 years as a family physician I have been honored to care for patients across the clinical spectrum, from birth to death. Birth and death provide poignant moments for personal reflection and a deeper understanding of the richness and power of human relationships. Both also offer the opportunity to develop a continuum of trust that defines itself over months (pregnancy) and days to months (end of life). In the initial encounter the patient brings varying degrees of doubt about his or

This article was externally peer reviewed.

Submitted 14 April 2007; revised 10 August 2007; accepted 15 August 2007.

From the Family Medicine Residency, Mercy Medical Center North Iowa, Mason City.

Funding: none.

Conflict of interest: none declared.

Corresponding author: W. David Clark, MD, Mercy Medical Center North Iowa, Mercy Family Medicine Residency, 1000 4th St SW, Mason City, IA 50401 (E-mail: clarkw@mercyhealth.com). her ability to endure the challenges ahead. Fears and anxieties about the unknown may or may not be articulated. Sometimes these initial meetings have elements of antagonism or hostility toward physicians or the medical system. Taking time to explore the story behind those feelings and perceptions has usually rewarded me with insight that has allowed me to give more compassionate and comprehensive care to both my pregnant and dying patients.

In the early 1980s, just out of my family medicine residency, I worked at a National Health Service clinic in rural Missouri. One day a woman approximately 24 weeks pregnant came into my office and was obviously unhappy that she had to talk to me. She was quite abrupt and made it very clear to me that she didn't like doctors. She wanted me to take care of her until she was close to her due date; she then intended to go with her husband to an alternative birthing center several states east, where a midwife would deliver her baby. All she wanted from me was prenatal care to reassure her there was nothing wrong that would prevent her from making this trip as her due date approached. My first inclination was to not involve myself in such expectations. Not only was this a strongminded, opinionated woman with whom I could foresee having numerous conflicts over the management of her care, but I also saw the potential medical-legal burdens. As I spoke with her I learned that her first child had died during childbirth; because of the elevated risks in this pregnancy I felt obliged to help her. We finally negotiated that I would give her care until 36 weeks of 
gestation, and she could then travel east and make arrangements for a midwife to assume her care. I saw her for 3 or 4 more visits. She begrudgingly accepted my advice to have some blood work and an ultrasound. Each time she came to my office she was a little less hostile and more communicative. On the fourth visit she confided to me what had happened when her first baby died. She had wanted to have her baby at home. No medical doctors were willing to do a home delivery. She had no prenatal care. She talked a local chiropractor into attending her birth at home. The baby, a girl, was born breech and died shortly after birth. She told the story in a detached, matter-of-fact manner, but she couldn't completely hide her sadness.

At approximately 34 weeks into her pregnancy I asked her what she had done about making arrangements for her trip east to see the midwife. She said, "I've been thinking about that. My husband and I don't have the money to go. Would you deliver my baby at our home?" Of course I said no. I talked to her about the need to be in a hospital if unforeseen problems arose in labor and delivery. She finally consented to having the baby in the hospital, but insisted on no preps, no IV, no monitors, and no pain medication. I actually felt honored that she asked me to be a part of her delivery. It symbolized to me that some level of trust had been established between us. The day of her delivery finally came and she was in the hospital, laboring just the way she wanted. We respected her wish to be left alone with her husband, who supported her very well during her labor. The nurse and I came in when she had more urgency to push, and a short time later her baby was born. Her first words, the expected "Is it OK?" were followed almost simultaneously by the baby's first cry, and mom squealed with delight. Then she asked the second question all moms ask: "Is it a boy or a girl?" I said, "It's a girl." She shrieked loudly, threw her arms around her husband's neck tightly, wept uncontrollably for approximately 2 minutes, and said over and over, "It's a girl. It's a girl." The nurse was crying. I was crying. We were witnessing redemption and joy. The patient and I were near the end of the continuum of trust, and it was powerful beyond words. An experience I have treasured for many years could have been missed had I not taken the time to understand my patient's perspectives at that first clinic visit.
As I have become more involved in palliative medicine I see how much my pregnancy care experiences helped prepare me for my new role. Pregnancy care and end-of-life care include the understanding that there is no way we know exactly how events will transpire, but we agree to communicate openly and honestly with each other and get through the situation together. I recently experienced this dynamic while talking with a young man with a progressive degenerative neurological disorder; he tearfully confided in me the hidden fears and anger that he had not been able to express to his loved ones. During our first encounter I had seen only dogged determination and a desire to control the circumstances of his illness. Only as trust developed could we talk about the deeper issues.

Family physicians have traditionally valued the continuity of relationships when caring for pregnant women, but maintaining this perspective has been challenging in our current health care environment. In a recent national survey of 1583 women, $29 \%$ of the mothers had never or had only briefly met the person who delivered their baby. Sixteen percent had 4 or more people who took the lead in providing prenatal care. ${ }^{1}$ The systems that foster discontinuity (and sometimes dissatisfaction) in maternity care mirror those near the end of life. Patients often encounter multiple consultants who communicate poorly with one another.

The early 20th century saw the beginning of the institutionalization of birth and death in the United States. ${ }^{2}$ Pregnancy care has become progressively more medicalized, with technology intruding into the patient-nurse-physician relationship. Some of this technology, despite the significant changes in obstetric practice that came with it, resulted in minimal net benefit for laboring patients and their babies. $^{3,4}$ The allure of technology has too often influenced sub-specialty physicians caring for patients at the end of life. Palliative medicine physicians often find themselves in highly technological environments. They are confronted with multiple consultants, each with their own single organ focus. Too often these consultants collectively move down well-intentioned but ineffective pathways that enmesh patients in persistent physical suffering, fear, and feelings of abandonment. What patients and their families desire both in pregnancy and at the end of life are clear communication, preservation of decision making, and respect. ${ }^{5-7}$ 
Table 1. The Role of the Physician in Pregnancy and End-of-life Care

- Be readily available

- Provide effective and timely pain relief

- Address relational and spiritual suffering

- Address emotional suffering (fear, realization that there is no turning back, exhaustion, helplessness)

- Provide accurate and relevant information about the process to patient and family members

- Respect cultural and religious customs and rituals surrounding the event

- Recognize the situations requiring action and those requiring patience

- Accept and encourage the presence of loved ones at the bedside

- Recognize that birthing and dying are unique to each individual and family; avoid a "cookbook" approach

- Understand that trust in the caregivers is important in achieving a desirable outcome

- Recognize that effective management enhances positive memories for the patient, family, and caregivers

It is doubtful that either birth or death will ever be fully understandable or predictable. Effectively caring for patients in both circumstances requires trust between the patient and the physician. I believe family physicians have had significant preparation to move into careers in palliative medicine because of the similar role that the physician assumes in pregnancy care and end-of-life care (Table 1). End-of-life encounters will continue to be a part of an active family medicine practice even without formal palliative medicine training. Family physicians drawn to the bedside of the end-of-life patient may be considering a full-time career in palliative medicine. Unknowingly they may now be palliative medicine apprentices.

\section{References}

1. Corry MP. Maternity Center Association. Recommendations from listening to mothers: the first national U.S. survey of women's childbearing experiences. Birth 2004;31:61-5.

2. Lindheim R. Birthing centers and hospices: reclaiming birth and death. Annu Rev Public Health 1981; $2: 1-29$.

3. Clark SL, Hankins GVD. Temporal and demographic trends in cerebral palsy-fact and fiction. Am J Obstet Gynecol 2003;188:628-33.

4. Green MF. Obstetricians still await a dues ex machina. N Engl J Med 2006;335:2247-8.

5. Marshall JF. What do women want? What do we think women want? Obstet Gynecol Surv 2004;59: 487-8.

6. Terry W, Olson LG, Wilss L, Boulton-Lewis G. Experience of dying: concerns of dying patients and carers. Intern Med J 2006;36:338-46.

7. Schockett ER, Teno JM, Miller SC, Stuart B. Late referral to hospice and bereaved family member perception of quality of end-of-life care. J Pain Symptom Manage 2005;30:400-7. 